\title{
METHODS IN TEACHING INDUSTRIAL MECHATRONIC SYSTEMS
}

Explanation in courses from the field of mechatronics is enough difficult due to the complexity and variety of phenomena to be explained. The introduction of computer based learning enables to make the learning easier and visualisation of variables offers a deeper insight in the system behaviour. Moreover, the introduction of e-learning into the teaching praxis makes learning in the courses more attractive for students and easier for the understanding of the presented subject. The paper describes the e-learning support of the study programmes in industrial mechatronic systems. Topics in e-learning modules are structured hierarchically starting from a system level in order to face the students with an increased complexity (top down approach). Introduced interactivity and animations allow the students to acquire a possibly deep insight into the complex and dynamic interactions of a number of parameters in the mechatronic systems.

\section{Introduction}

Industrial products are becoming more and more sophisticated and more complex. Continuous industrial manufacturing belongs among the most effective technologies. The manufacturing lines present mechatronic systems in industrial environment. Here, the technological operations are performed continuously on the material in form of a strip (of steel, paper, plastic, rubber, etc.), that moves continuously from one working machine to another. The production lines of such types occur in various areas of industry, e.g. in paper making machines (paper strips production), rolling mills (steel strips), production lines in chemical industry (plastic fibres and strips), and in many other industries. In fact, the processed material causes a mechanical coupling of electrical drives driving the working machines which increases complexity of the system and introduces some problems at its control.

Such a mechatronic system requires a concurrent design of mechanical, electronic, and information processing sub-systems in order to reach the cost requirements of the industry. The growing importance of mechatronics requires adequately prepared specialists. Regardless of whether the mechatronics is explicitly mentioned, almost all engineering schools have given serious thoughts and enhanced their programs so that their graduates are ready to successfully face today's industrial challenges and practice mechatronics, as discussed detailed in [1]. Nowadays, when the students incline more to the fields of study of informatics and telecommunications, education in the field of electrical and mechatronic engineering is really troublesome job [2]. The steadily decreasing ratio of the students interested in studying "soft and clean" branches of study like informatics and telecommunications to the students dealing with electrical- and electro-mechanical engineering (considered generally as "hard and muddy" ones) has led to lack of specialists in the field in many European countries.
A mechatronic engineer is an ideal solution to the problem faced by complex industrial environment but there are very few engineers of this type available. This is mainly due to the fact that the students are not encouraged to move into this field. Mechatronic courses need to be marketed in a different way, by making them more attractive, although they are seen to be difficult ones. The students need to be aware of rewards and acquired knowledge and of the fact that manufacturers have difficulty in finding these type of engineers. It is the job of the university teachers to make studying more attractive and easier accessible [3]. Web based learning tools help to contribute to fulfilment of the presented goals.

\section{Object of industrial mechatronics curricula}

Manufacturing lines equipped with motion control represent industrial mechatronic systems. In Fig. 1, a control structure of tandem hot-mill line is shown, that presents a typical multi-motor drive system with mechanically coupled drives. Appearance of dis-

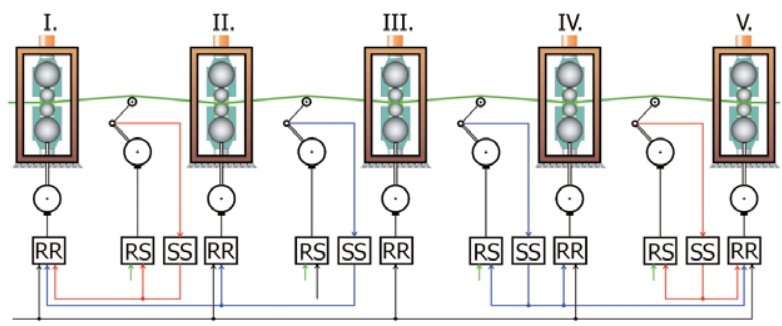

Fig. 1 Control structure of a tandem hot rolling mill as an example of a large industrial mechatronic system (RR - speed controller, $R S$ - looper motor controller, SS - looper position sensor)

\footnotetext{
* Viliam Fedák ${ }^{1}$, Pavol Bauer ${ }^{2}$

${ }^{1}$ Faculty of Electrical Engineering and Informatics, Technical University, Košice, Slovakia, E-mail: Viliam.Fedak@tuke.sk

${ }^{2}$ Delft University of Technology, Delft, The Netherlands, E-mail: P.Bauer@tudelft.nl
} 
turbance (caused e.g. by inhomogenity of the processed material) in one section influences the strip tension and thickness of the material elsewhere. Thus it affects the behaviour of the whole group of drives. To eliminate this effect sophisticated control structures and algorithms are used.

A detailed analysis shows that such industrial technologic line has all attributes of a mechatronic system, consisting of mechanical, electrical and control (information processing) parts (Fig. 2a). Control of such a complicated system with many mutual couplings and dependencies requires a deep knowledge from all fields of mechatronics: mechanical, electrical and information engineering.

There are plenty of mechatronic systems of various complexities and ranges. For example, an electrical drive itself can be also considered as a mechatronic system, although a simpler one, that integrates various subsystems and knowledge from mechatronics (Fig. 2b).

When designing controllers for a single electrical drive, influence of the environment is replaced by a load torque. In case of analysed multi-motor drive, a complex multivariable system arises causing difficulties in its control. Knowledge of a graduate in electrical engineering is usually in this case unsatisfactory. The knowledge from mechanical engineering as well as production technology is also required. Without following a specialised course on mechatronics, the specialist is not able to deal with the control of such complex plant as described here.

A general problem in mechatronics is the fact that the explanation deals with rather abstract notions (e.g. for electrical engineering they are current, voltage, resistance, capacitance etc.). It has been found that students who have faced with the principles of fundamental courses (electronics, power electronics, control theory, ...) have problems in understanding the phenomena in complex mechatronic systems where the main feature is a large number of simultaneously occurring variables and changes of various substance, where the variables can vary with time, can be mutually dependent, depend on state of other system variables, etc.
Teachers may clearly discuss all the phenomena involved during lectures. However, even if computer animations are used, the students cannot grasp the details in a short time, since the teacher only once or twice shows examples or animations. There remains a need for repetition and exercises. As a side problem, students tend to get de-motivated by this complexity. This leads to the undesirable situation that increases the discrepancy between the number of students in mechatronic engineering and the demands from industry for engineers in this field. After some considerations it was decided to develop a number of computer animations showing in a systematic and consistent way the interactions of switching states, currents and voltages of different circuits of a mechatronic system.

\section{Basic philosophy of e-learning platform for courses on mechatronics}

The most important task at beginning of design and development of an e-learning material is its philosophy. This covers the appearance of the screens (environment), mutual linking of the screens (screen flow), introducing animation and simulation tools, introducing interactivity (external change of structure and parameters of the system), and, last but not least, presenting a way of explanation and description of phenomena on the screen and other ideas.

Each good e-learning material for mechatronics should evidently clarify the phenomena and variables that are not directly visible. In fact, nobody sees the current, voltage, mechanical stress, force, etc., but their consequences are apparent. This is why a good e-learning material should contain interactive animations to show the phenomena-component-circuit-system behaviour. The introduced interactivity brings a new dimension into education by showing and evaluating influence of a variable parameter. A possibility to change a circuit and/or system parameter by shifting a slider or inserting the parameter value presents a presumption of the system analysis.

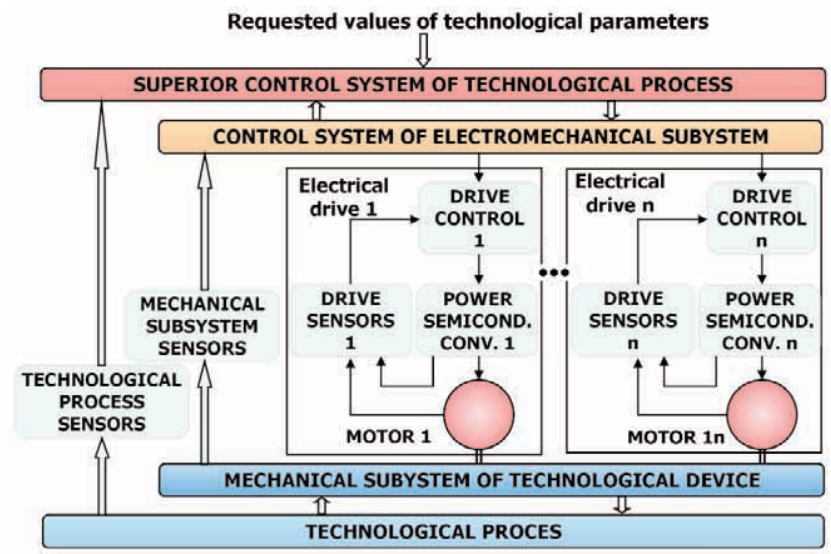

a)

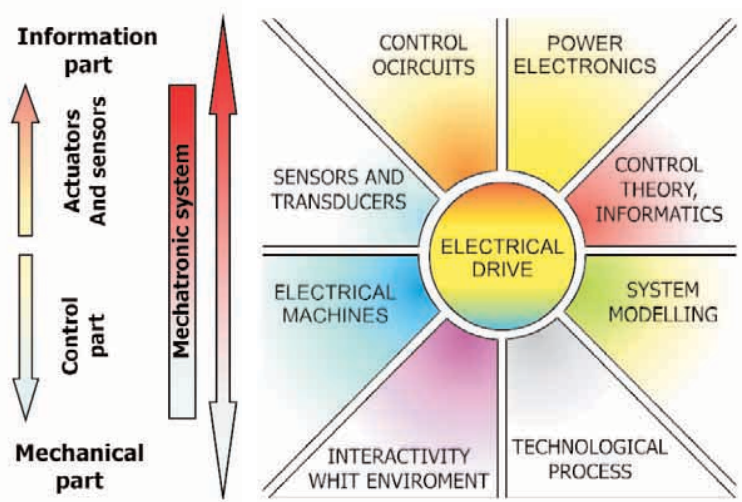

b)

Fig. 2 Decomposition of mechatronic systems into subsystems: a) multi-motor drive of the hot rolling mill, b) electrical drive 
Further key point of a good e-learning material is the way of theoretical explanation. It is not a simple question which amount of textual explanation is necessary to make the basics understanding, but not too much to become boring. This fact depends on a target group - on the audience for whom the e-learning material is prepared. These are the reasons why it is difficult to design a proper e-learning material:

- if the tools are utilized as a complementary part of the lectures at the university, then the theory is mostly explained by the teacher, and the lecture notes, handouts can be used as the main source,

- short explanations in form of flowing windows appearing after any mouse activity (running over the picture, pushing buttons, etc) are usually also enough for the qualified engineers, who would like only to refresh or update their knowledge,

- much deeper theoretical explanations should be provided if the main objective is the distance learning, since the learners are expected to study most of the curriculum alone, after their work or on the weekends.

The wide spectrum of key courses to be studied in the BSc. and MSc. degrees study programmes on mechatronics covers all three fields of the mechatronics: mechanical, electrical and information engineering, mutually penetrating themselves [11].

\section{Examples of e-elarning modules}

The most important parts which the mechatronic motion systems consist of are the system mechanics, electrical system consisting of integrating power electronic converter, electrical drive, and the information part covering control system with implemented control algorithm. Let's show several typical examples.

\subsection{System Mechanics}

A large part in the curricula of courses on mechatronics is devoted to explanation of mechanic of more complex systems that

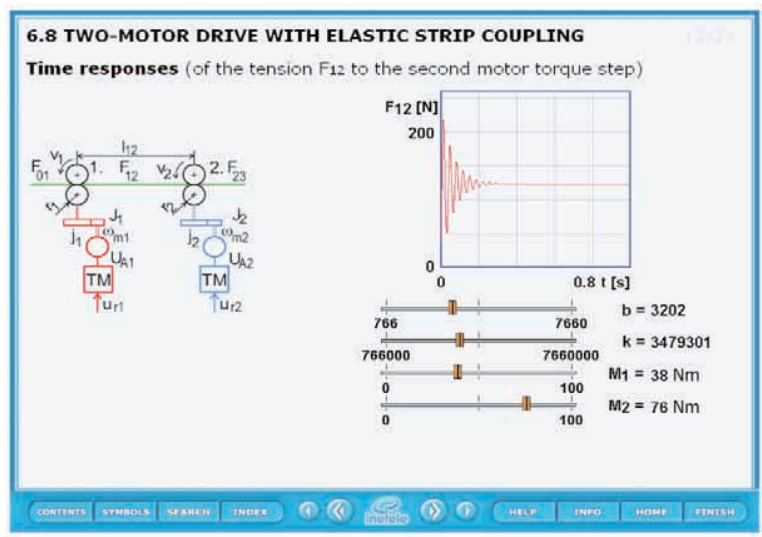

a) in our case are presented by the multi-motor drives. Their behaviour depends on the mutual mechanical coupling properties, in our case on the form and mechanical properties of the processed material. The screen in Fig. 3a shows a simple simulation of a twomotor drive where the student can adjust elasticity and damping of the strip material and to observe their influence to oscillations of the tension in the strip. The parameters are set continuously, by a slider. The students do not learn the properties of the system only from simulation but they have a chance to verify the simulated results on the laboratory model of a technological line (Fig. $3 b)$ that of a coiler and uncoiler, and three driven cylinders transporting the strip. Altogether five drives are mechanically coupled through the strip. In the laboratory model, the tension in the strip in each loop is measured by a position of a simple swinging arm whose force can be separately adjusted. On the right side of the figure a multiprocessor control system is shown.

Fig. 3a shows the full screen with the menu where the buttons enable to control the screen flow and other supported functions (e.g. to get the Contents, Symbols, Index, Help and more information). In order to show the screens in the following figures simpler, the menu is further omitted. The number in the left upper corner of the screens assigns the chapter number of the developed multimedia e-learning module.

\subsection{Power Electronics}

Power electronic converters are the main actuators of electrical motors in the drive system. When studying a certain power electronic circuit, the first question of the student is always for the different current paths in dependency of the switching states and certain impressed currents and voltages. With traditional teaching a current paths are drawn using different colours into some figures of the power circuit, or the teacher presents slide-shows in the classroom. Here the approach of interactive animations is used.

To illustrate the ideas mentioned above an example is shown here. The square wave generation principle shown in Fig. 4 pre-

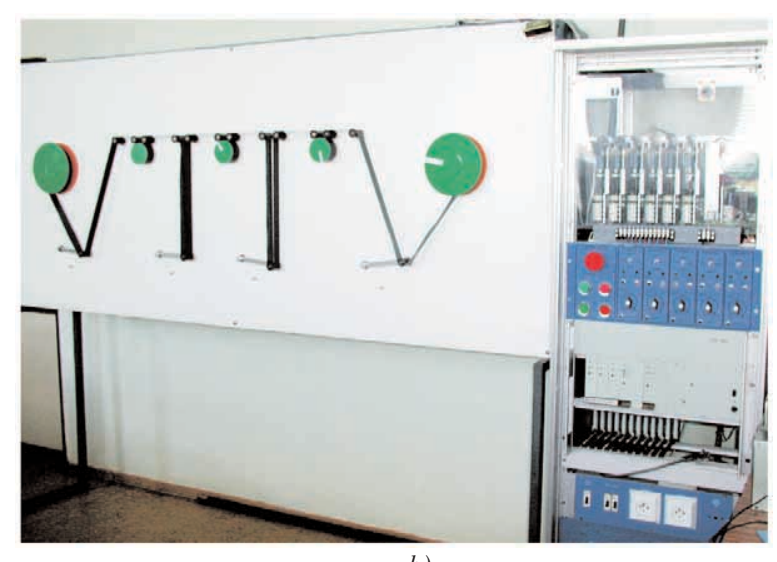

b)

Fig. 3 A multi-motor drive with mechanical coupling through the strip of the processed material as an example of an industrial mechatronic system: a) block diagram with time response of the strip tension, b) laboratory model 


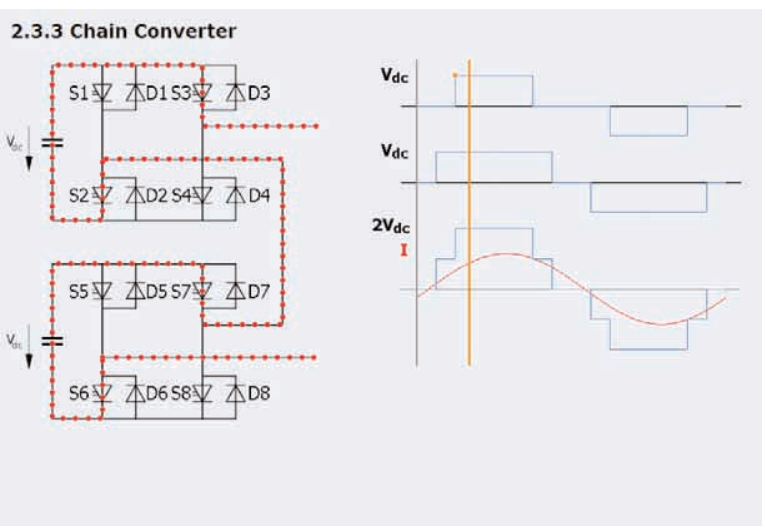

Fig. 4 A single-phase structure of an m-level cascade inverter

sents a basic switching strategy used for high power converters. The continuously running animation was replaced by a static one where the cursor (orange vertical line in the time diagram) can be shifted in time. This solution gives a possibility to explain circuit behaviour given by switching states of the power semiconductor devices in the required time instant. The chain circuit represents a straightforward approach to the realisation of a multi-level converter for use in high power applications without the need for magnetic combining circuitry and complex transformer arrangement. The main advantage of this approach is the well-defined operating environment for each three-level pole within a substantially isolated H-bridge circuit.

\subsection{Electrical Drives}

In an open-loop drive system, consisting of a power electronic converter and motor, the students learn properties of the drive from time courses of the system typical variables (voltages, currents, magnetic fluxes, motor torque and shaft speed) in the dynamic and steady-state states.

A typical example from the field of AC electrical drives supplied by a voltage-source inverter (VSI) in Fig. 5 shows time courses

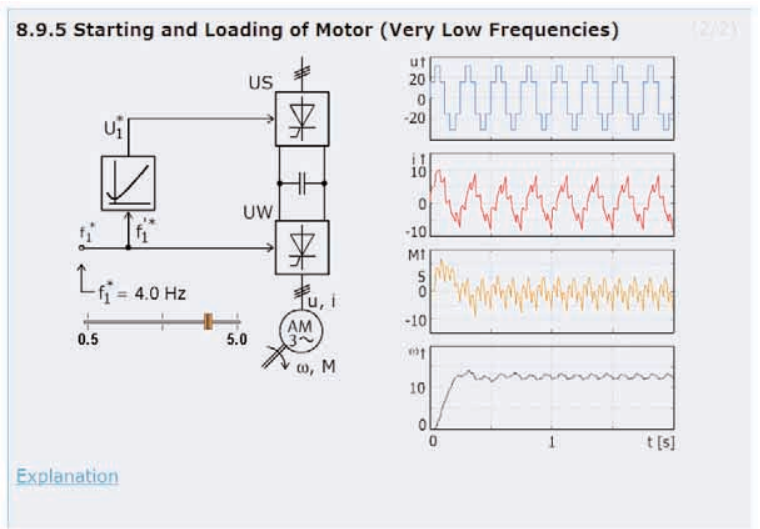

a)

Fig. 5 AC drive with VSI: animation of drive behaviour in area of low (a) and higher (b) frequencies of the drive typical variables - the phase voltage of the motor, the stator current, the electrical torque and the speed.

The student can set up the frequency of the inverter switching and thus study influence of the six-pulse converter switching on the motor behaviour, separately at low frequencies where the oscillation of the speed occurs and at higher frequencies. The frequency is set by the orange colour slider. The built-in switch enables to demonstrate frequency starting and direct connection of the induction motor to the pre-set frequency. More advanced topics deal with eliminating the torque and speed oscillations by introducing other switching algorithms (different PWM techniques) for the inverter.

\subsection{Motion Control}

Here, the students learn various motor control structures and a design of motor controllers from the point of view of ensuring performance criteria. The most important is to explain the system behaviour, to show the procedure for controller parameters calculation and to show the time courses of the inner and output drive variables.

To eliminate sensors, the control structures of modern drives involve also observers of inaccessible system variables. Fig. 6 shows an example of a linear state and disturbance observer [10]. Their time courses of observed state variables and disturbance are shown after opening the block of the scope as shown in the Fig. $6 b$.

Necessary calculations for the observer gains would disturb the attention of the students at explanation of performance the observer. This is the reason why they were put in the secondary screen which is opened after clicking on the "Example" button. The observer parameters are calculated based on the system eigenvalues and observer chosen eigenvalues (i.e. on the desired characteristic polynomial). Based on the procedure, the student can calculate observer parameters for own system.

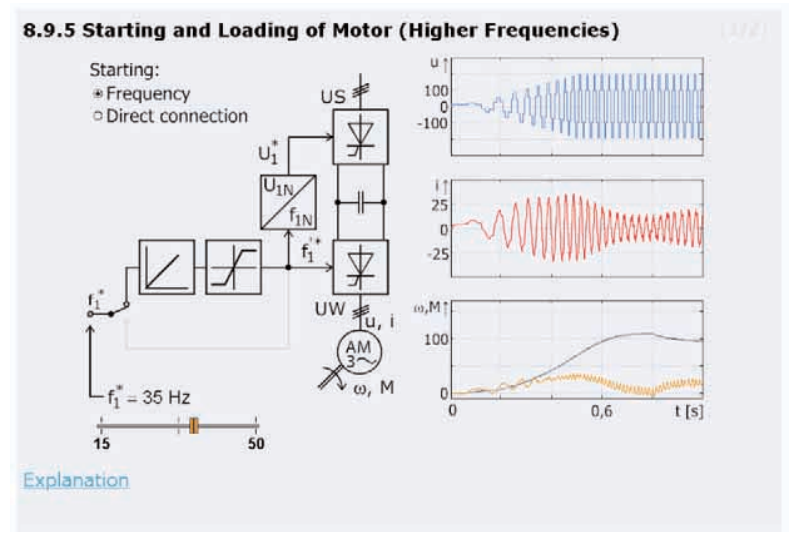

b)

50 - KOMUNIKÁCIE / COMMUNICATIONS 1/2007 


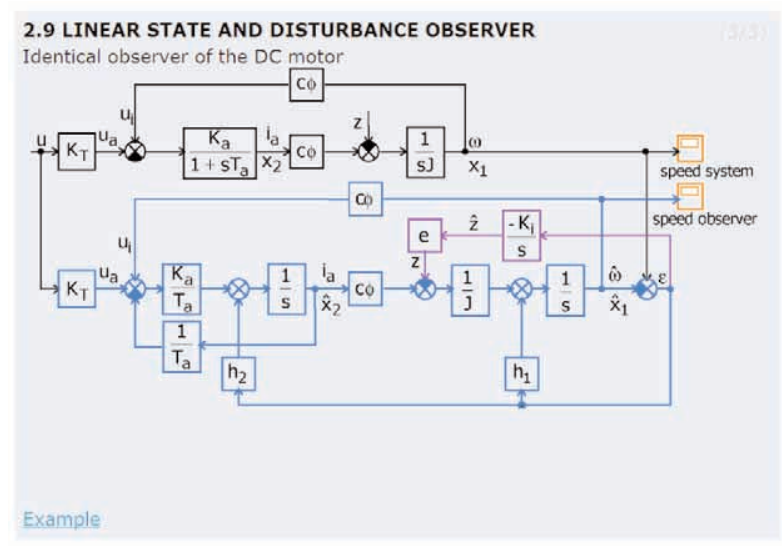

a)
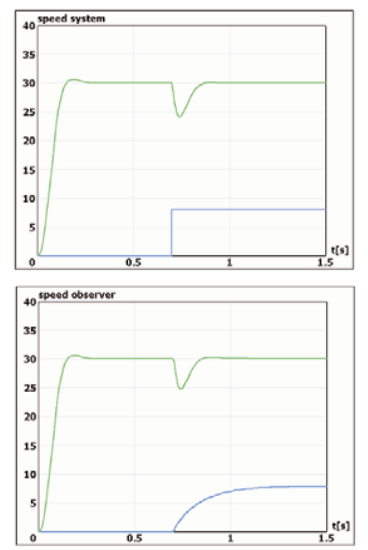

b)

Fig. 6 a) Block diagram of a DC drive with state and disturbance observer and b) time responses of the actual and observed speed and disturbance (load torque)

\section{Conclusions}

The paper gives an overview of needs and skills required by the engineers working in the mechatronic system environment. After a brief presentation of the background of the curricula in mechatronics the paper shows philosophy of the web based interactive modules supporting the courses. They were developed not only in order to make education easier but also with the aim to attract the students to follow the accredited courses on mechatronics. On several screens there are some typical results from realised e-learning modules presented, enhancing the used philosophy and ways of visualisation.
The e-learning approach helps to understand coherences in complex mechatronic systems but it presents a part of education only. The training is also supported by a laboratory equipment where the students get practical experience.

The animations in the modules were realised in Macromedia Director environment and finally implemented in the html using Macromedia Dreamweaver. The Macromedia software can develop interactive graphical user interfaces that are easy to use.

\section{References}

[1] 2nd IFAC Conference on Mechatronics Systems, Dec. 2002 Berkeley, California, www.unex.berkeley.edu/eng/mech/

[2] BAUER, P., KOLAR, J.: Teaching Power Electronics in 21 Century, EPE Journal, vol. 13, Nov.-Dec./2003, ISSN: 0939-8368.

[3] UNDELAND, T. M., MOHAN, N.: Teaching Electric Machines and Drives: A re-examination for the new millennium, $11^{\text {th }}$ Int. Power Electronics and Motion Control Conf. (EPE-PEMC 2002), Dubrovnik, Croatia, 2002.

[4] FEDÁK, N., BAUER, P., HÁJEK, V., WEISS, H., DAVAT, B. et al: Interactive e-Learning in Electrical Engineering, Int. Conf. on Electrical Drives and Power Electronics (EDPE'03), The High Tatras, Slovakia, pp. 368-373, 2003, ISBN 80-89114-45-4.

[5] BAUER, P., FEDÁK, V.: Educational Visualization of Different Aspects for Power Circuits and Electrical Drives, $11^{\text {th }}$ Int. Power Electronics and Motion Control Conf. (EPE-PEMC 2004), Riga, 2004, ISBN 9984-32-010-3.

[6] FEDÁK, V., REPISCAK, M., ZBORAY, L.: Design and Implementation of E-Learning Tool for Courses on Electrical Drives, Int. Conf. on Electrical Drives and Power Electronics (EDPE 2005), Dubrovnik, 2005, CD ROM - E05-115, ISBN 953-6037-43-2.

[7] UNDELAND, T. M.: There is a Need for Changes in PE\&ED Education at Universities, EPE Journal, 1/2002, ISSN: 0939-8368.

[8] FEDÁK, V., FETYKO, J.: Interactive Solutions Design for E-learning Course on Mechatronics, $3^{\text {rd }}$ Int. Conf. on Emerging Telecommunications Technologies and Applications (ICETA 2004), elfa, Košice, 2004, 431-433, ISBN 80-89066-85-2.

[9] HAMAR, J., FUNATO, H., OGASAWARA, S., NAGY, I.: New E-Learning Tools for DC-DC Converters, $11^{\text {th }}$ Eur. Conf. on Power Electronics and Applications (EPE 2005), Dresden, ISBN 90-75815-08-5, IEEE Cat. Number: 05EX1132C.

[10] ZBORAY, L.: Controlled Drives, E-learning module. INETELE, VUT Brno, 2005, ISBN 80-214-2978-X

[11] FEDÁK, V., FETYKO, J.: New Courses on Large Industrial Mechatronics Systems at the FEEI TU Kosice, Int. Conf. on Electrical Drives and Power Electronics, EDPE 2005, Dubrovnik, 26-28 Sept. 2005. CD ROM - E05-114. ISBN 953-6037-43-2.

[12] FEDÁK, V., ĎUROVSKÝ, F., FETYKO, J.: Web-Based Support of Courses in Industrial and Automotive Mechatronics, $12^{\text {th }}$ Power Electronics and Motion Control Conf. (EPE-PEMC 2006), Portorož, 2006. ISBN 1-4244-0121-6. IEEE Cat. Number 06EX1282C, pp. 2118-2123.

[13] SÜTÖ, Z., NAGY, I.: Nonlinearity in Controlled Electric Drives: Review, IEEE ISEIE 2006, July 9-12, Montreal, pp. 2069-1076. 